\title{
Subgaleal coiling of the proximal and distal components of a ventriculoperitoneal shunt
}

\author{
Brian T Kloss ${ }^{1 *}$, David M Hart ${ }^{2}$ and LaLainia Secreti ${ }^{1}$
}

\begin{abstract}
Migration is a rare complication of venticuloperitoneal shunts and is thought to be associated with the "memory" of the plastic tubing and the windlass effect of neck flexion and extension. The purpose of this case report is to detail a very rare case of complete distal to proximal shunt migration.
\end{abstract}

\section{Case Report}

An 11-month-old female with a history of multiloculated, complex intracranial cysts with shunt-dependent hydrocephalus and seizure disorder presented to the emergency department with a 2-day history of lethargy, sleepiness, nausea and vomiting. The patient was 3 days status post insertion of a left ventriculoperitoneal shunt insertion. Vital signs were stable, and physical exam revealed a large subgaleal mass at the left occipital area. (Figures 1 and 2) Skull films (Figures 3 and 4) and head CT (Figures 5 and 6) revealed that the shunt catheter was located completely outside the cranium and contained within it a $3.4 \times 5.1 \times 4.0$-cm subgaleal fluidfilled pocket. The child was taken back to the OR, and a new shunt catheter was placed without complication. The child has since been doing well.

Significant proximal shunt migration is an extremely rare complication that has only been reported in the literature on six occasions [1-5], with the full migration of the distal and proximal aspects of the shunt catheter into a subgaleal pocket reported only twice $[2,4]$. The proposed mechanism for the migration of the catheter involves the "windlass" effect combined with the retained "memory" of the shunt tubing [2]. The flexion and extension of the child's neck in the days following the surgery combined with the "memory" of the plastic tubing were the likely culprits causing the shunt migration.

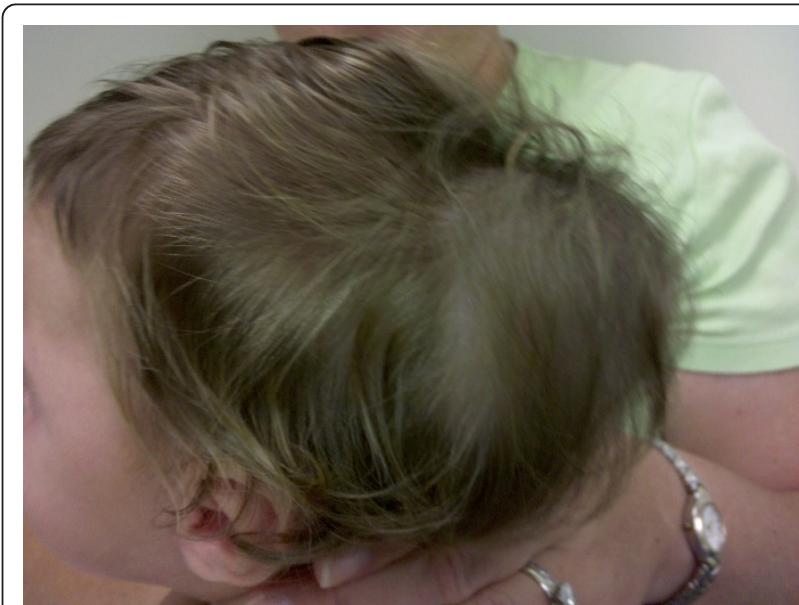

Figure 1 Side Photograph Showing Coiled Shunt.

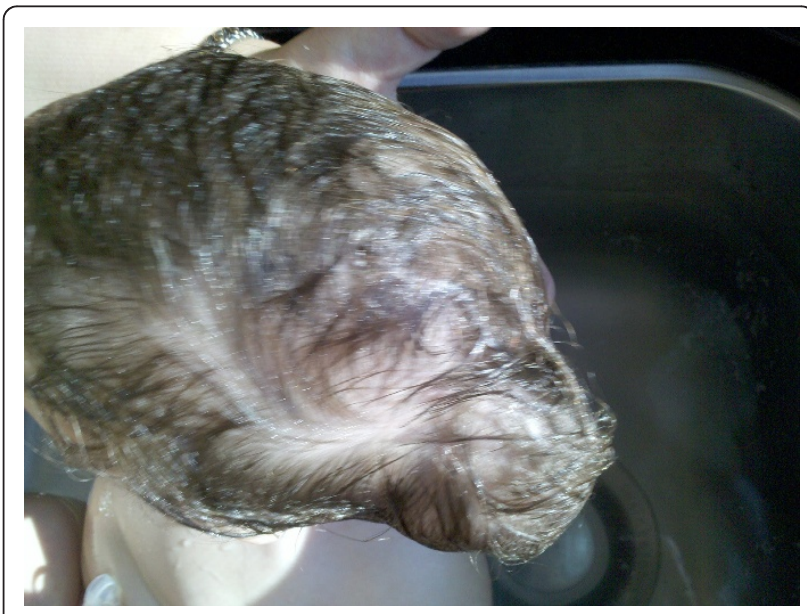

Figure 2 Top Photograph Showing Coiled Shunt 


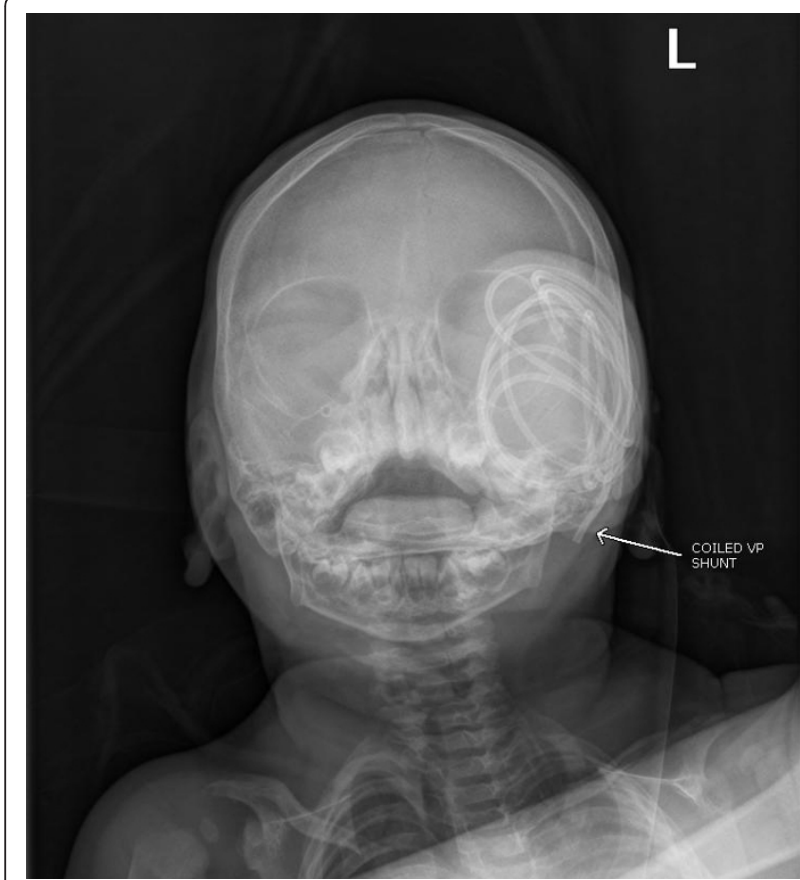

Figure 3 AP Skull Showing Coiled Shunt

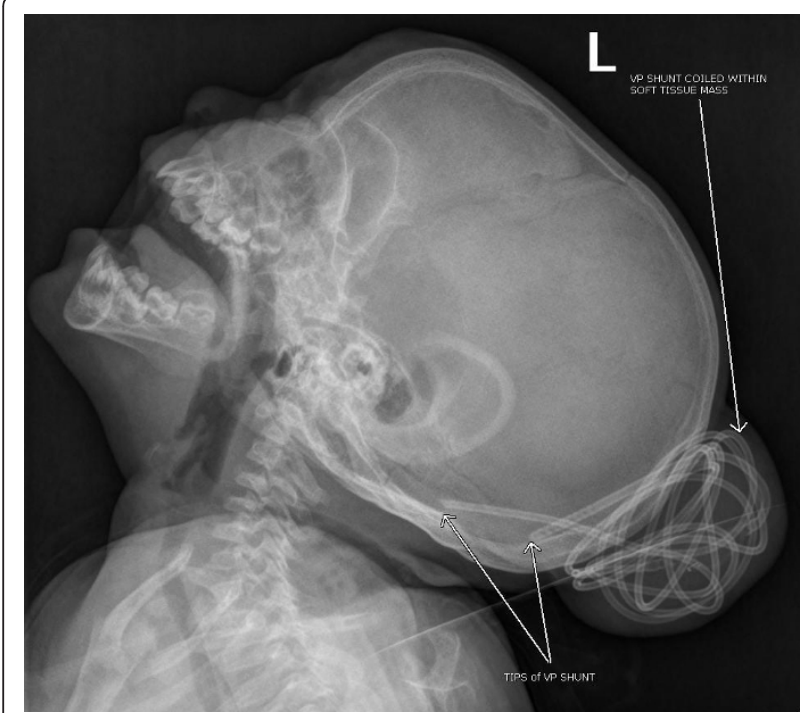

Figure 4 Lateral Skull Showing Coiled Shunt

\section{Author details}

'SUNY Upstate Medical University, Syracuse, NY 2 University of Rochester Medical Center, Rochester, NY

\section{Authors' contributions}

BK oversaw and edited the case report and the organization of the images as published. $\mathrm{DH}$ researched the current literature and wrote the body of the paper. LS oversaw patient care in the ED and obtained verbal and written consent for publication. All authors read and approved the final manuscript.

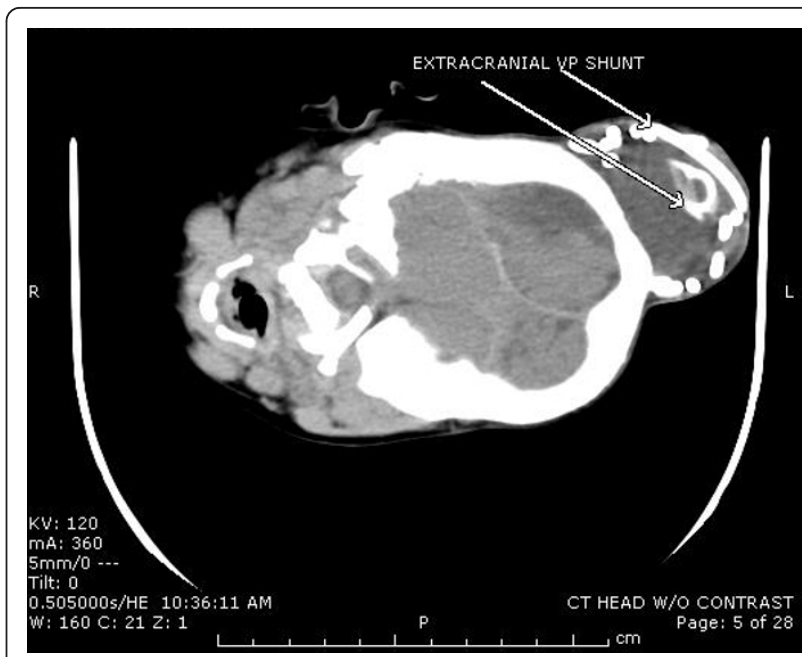

Figure 5 Cross Section CT Showing Coiled Shunt.

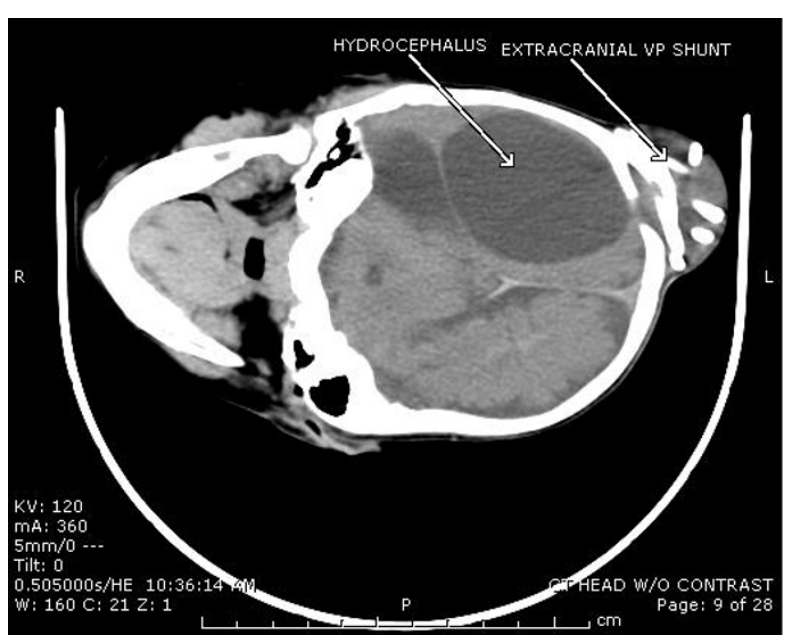

Figure 6 Cross Section CT Showing Coiled Shunt and Hydrocephalus.

\section{Competing interests}

The authors declare that they have no competing interests.

Received: 15 November 2010 Accepted: 16 March 2012

Published: 16 March 2012

\section{References}

1. Cheng JY, Lo WC, Liang HH, Kun IH: Migration of ventriculoperitoneal shunt into the stomach, presenting with gastric bleeding. Acta Neurochir (Wien) 2007, 149(12):1269-70.

2. Dominguez CJ, Tvagi A, Hall G, Timothy J, Chumas PD: Sub-galeal coiling of the proximal and distal components of a ventriculo-peritoneal shunt. An unusual complication and proposed mechanism. Childs Nerv Syst 2000, 16(8):493-5.

3. Fewel ME, Garton HJ: Migration of distal ventriculoperitoneal shunt catheter into the heart. Case report and review of the literature. $J$ Neurosurg 2004, 100(2 Suppl Pediatrics):206-11.

4. Heim RC, Kaufman BA, Park TS: Complete migration of peritoneal shunt tubing to scalp. Childs Nerv Syst 1994, 10(6):399-400. 
5. Kim KJ, Wang KC, Cho BK: Proximal migration and cutaneous coiling of a peritoneal catheter: report of two cases. Childs Nerv Syst 1995, 11(7):428-31.

doi:10.1186/1865-1380-5-15

Cite this article as: Kloss et al:: Subgaleal coiling of the proximal and distal components of a ventriculoperitoneal shunt. International Journal of Emergency Medicine 2012 5:15.

\section{Submit your manuscript to a SpringerOpen ${ }^{\mathcal{O}}$ journal and benefit from:}

- Convenient online submission

- Rigorous peer review

- Immediate publication on acceptance

- Open access: articles freely available online

- High visibility within the field

- Retaining the copyright to your article

Submit your next manuscript at $>$ springeropen.com 